\title{
Predictors of waiting time for coronary angioplasty in a high risk population
}

\author{
Brian Gaffney, Frank Kee
}

\begin{abstract}
Objective-To describe the clinical and non-clinical factors which influence the waiting time from initial angiography to angioplasty.
\end{abstract}

Design-Follow up of a random sample of 106 patients undergoing their first coronary angiography for whom a decision to revascularise by percutaneous transluminal angioplasty was made in 1991. The period between the date of angiography and the date of angioplasty and various clinical characteristics of patients were retrieved from medical notes in mid1993. Patients were sampled from those investigated in the two Northern Ireland catheterisation laboratories in Belfast, which provide services for the whole of the province (population 1.5 million).

Main measures-The dependent variable was the period between initial angiography and angioplasty, and the independent variables included age, sex, distance from cardiac catheterisation centre, referral source, characteristics of the clinical history, severity of angina, and anatomical extent of disease. Cox's proportional hazards analysis was used to derive a relative hazard, expressing the relative chances of revascularisation occurring at any time during follow up. Results-Of the 106 patients studied, 93 had had percutaenous transluminal angioplasty at follow up. The most important predictors of waiting time were the presence of severe angina (relative hazards $3 \cdot 1(95 \%$ confidence interval $(95 \%$ CI) $1 \cdot 4-6 \cdot 8)$ and $2 \cdot 7(1 \cdot 2-6 \cdot 2)$ for Canadian Cardiovascular grades III and IV $v$ angina grade I angina), a recent history of myocardial infarction (relative hazard, $2 \cdot 5(1 \cdot 3-4 \cdot 8)$, and whether or not the patient was economically active (relative hazard $0 \cdot 6(0 \cdot 4-1 \cdot 0)$ for economically inactive $v$ active patients). Although there was also an association with the relative deprivation of the area of residence of the patient it had no clear linear trend.

Conclusions-Although waiting time for percutaneous transluminal angioplasty was predictably related to the patient's clinical presentation, demographic factors may also be important in determining access to intervention. These factors clearly merit further study; ultimately, the evaluation of equity in a waiting time distribution may more properly be a societal rather than a clinical judgment.

(Quality in Health Care 1995;4:244-249)
Keywords: coronary angioplasty, waiting time, predictors, demographic factors

\section{Introduction}

Recently, the Clinical Standards Advisory Group highlighted the variation in access to revascularisation services across the country and one of the key concerns was the lack of clear criteria with which to prioritise patients. ${ }^{1}$ Similar sentiments have been expressed by the Scottish Home and Health Department ${ }^{2}$ and by the chief medical officer for Northern Ireland, ${ }^{3}$ where, despite improvements over the past decade, mortality rates from coronary heart disease are still among the highest in the world. Although the appropriateness of invasive assessment and revascularisation for coronary heart disease has previously been studied in the United Kingdom, ${ }^{4-6}$ little has been reported on the adequacy of the prioritisation process. The most notable research has been on what determines urgency for surgical revascularisation and is to be found in a series of reports from Ontario. ${ }^{7-12}$ Most of these studies have been based on the views of consensus panels or of surveyed specialists and seem to point both to clinician specific ${ }^{8-12}$ and to institution specific $^{12}$ variation in queue forming criteria. There are scant data in the United Kingdom with which to demonstrate the impact of clinical and non-clinical factors on waiting times for angioplasty. The need to monitor and promote equity for patients accessing such services has recently been highlighted. ${ }^{13}$ This study attempts to describe the effects of clinical and non-clinical factors in a randomly drawn cohort of patients from one region.

\section{Methods}

This study, initiated soon after the chief medical officer's report, ${ }^{3}$ forms part of a more comprehensive investigation into access to specialised cardiological assessment and treatment throughout Northern Ireland. Facilities for cardiac catheterisation (and angioplasty) in the province (population 1.5 million) are provided in only two hospitals, the Belfast City Hospital and the Royal Victoria Hospital, situated about one mile apart in Belfast. Each catheterisation laboratory maintains a register of daily activity which gives the patients' names and the types of procedures undertaken. In 1991 the Belfast City Hospital undertook 860 procedures and the Royal Victoria Hospital 1607. We generated a list of random numbers and with this selected a sample of 500 patients from the registers (weighted in proportion to their share of total activity). When the hospital notes indicated that the procedure undertaken

\author{
Ballymena BT42 1QB \\ Accepted for publication \\ 28 June 1995 \\ Correspondence to \\ Department of Public \\ Health Medicine, \\ Social Services Board, \\ County Hall
}


was not the first angiography carried out on that patient, the next eligible patient in the register was selected. The methods have been reported in detail elsewhere. ${ }^{14}$

The group studied consisted of the 106 patients for whom coronary angioplasty was the intended treatment as indicated at the time of a joint surgical and cardiological catheterisation conference. The medical notes of these patients were retrieved during the summer of 1993. We sought a range of information, including (a) age, sex, address (postcode and electoral ward), occupation, employment status, and referral source (from a cardiologist/ physician working in a Belfast hospital versus "other"); (b) smoking habit, body mass index, family history (any first degree relative aged under 65 with myocardial infarction or sudden cardiac death), comorbidity (any previous treatment for hypertension, diabetes, or hyperlipidaemia), and severity of angina (Canadian Cardiovascular Society grade ${ }^{15}$ ). Whether the angiogram was being performed after a myocardial infarction was also recorded. Because the Canadian Cardiovascular Society scale does not satisfactorily define unstable angina, ${ }^{16}$ only allowing within class IV that pain at rest "may be present," the presence of either severe angina, or unstable angina was categorised as one class. ${ }^{16}$ At the time of angiography, the total number of vessels with $>50 \%$ stenosis was recorded, as were the results of an exercise treadmill test if this was performed. For each patient, the waiting time from the date of angiography to the date of angioplasty (if it occurred during the follow up), was noted.

Because of the absence of the patient's occupation from most records and the consequent difficulty in coding social class, the usual area of residence was categorised according to the "material affluence" of the respective electoral ward by deriving a Townsend deprivation score. The score, previously shown to be associated with spatial and social variations in health indicators in Northern Ireland, ${ }^{17}$ is calculated as the sum of four equally weighted census variables (which were originally chosen explicitly to act as proxies for various aspects of a lack of control over material resources). These variables are the percentages of the ward population who are unemployed, have no car, live in overcrowded housing, and who are not owner occupiers. The resultant scores for the 566 electoral wards in the province (ranging from -5.63 to 11.07 (affluent $\rightarrow$ deprived) were ranked and then divided into quintiles based on this distribution.

The distance in a straight line between the patient's address and the catheterisation centre (range 0-90 miles (about 0-145 km)) was derived by simple trigonometry and the resultant distances grouped into quintiles.

Some continuous variables have been categorised into groups enabling univariate analysis of the effect of clinical and non-clinical factors on the time from angiography to angioplasty to be performed by calculating $\chi^{2}$ statistics for the log-rank test. ${ }^{18}$ All tests were two tailed.
Cox's proportional hazards analysis was used to adjust for important covariates. ${ }^{19}$ Patients who died or were lost to follow up before revascularisation were censored at that date and those who had not undergone revascularisation at the time of data abstraction were censored on that date.

In this analysis, performed with SPSS for Windows, the time from angiography to angioplasty was the dependent variable and the most important predictor variables were identified by stepwise (backward) elimination. The significance of any given variable was tested by assessing the difference in twice the logarithm of the partial likelihood of heirarchical models by $\chi^{2}$ test, with degrees of freedom equal to the difference in the number of parameters in the model. The derived relative hazards (and the $95 \%$ confidence intervals (95\% CIs)), express the ratio of the instantaneous chances of the outcome event (angioplasty) taking place in one group compared with another.

\section{Results}

Of the 106 patients for whom angioplasty was the intended treatment, 93 actually underwent the procedure during follow up. For those who underwent revascularisation the median waiting time to angioplasty was 20 days. Table 1 describes the clinical and non-clinical characteristics of the sample and indicates those variables which, in the log-rank test, were associated with the waiting time for treatment. In this univariate analysis, only age group and the relative affluence of the patient's usual area of residence were significantly associated with the waiting time.

There were some notable associations between variables. For instance, patients with a recent history of myocardial infarction were less likely to have severe anginal symptoms $\left(\chi^{2}=54\right.$, degrees of freedom $(\mathrm{df})=3$, $p<0.001)$. Those referred from hospitals outside Belfast were more likely to have severe angina $\left(\chi^{2}=7.99, \mathrm{df}=3, \mathrm{p}=0.046\right)$ and less likely to have a history of recent myocardial infarction $\left(\chi^{2}=3.66, \mathrm{df}=1, \mathrm{p}=0.056\right)$ or to come from a "well off" area $\left(\chi^{2}=9 \cdot 96, \mathrm{df}=4\right.$, $p=0.041)$. The younger patients were more likely to be economically active $\left(\chi^{2}=26, \mathrm{df}=2\right.$, $\mathrm{p}<0.001)$. After simultaneously adjusting for covariates and potential confounding, the variables which were predictive of waiting time in the Cox's proportional hazards model were the presence of a recent history of myocardial infarction, the severity of symptoms, the relative affluence of the patient's usual area of residence, and the employment state of the patient. Table 2 gives the relative hazards (95\% CIs) for these variables after adjustment for covariates. Those with severe symptoms (stable grade IV angina or unstable angina) were 2.7 times more likely to receive angioplasty than those with grade I disease. Independent of the severity of symptoms, the relative chance of revascularisation occurring during follow up were 2.5 times more likely if there was a recent history of myocardial infarction. After adjusting for age and sex, the economically inactive patients (unemployed 
Table 1 Univariate relation between predictor variables and waiting time for angioplasty

\begin{tabular}{|c|c|c|c|c|c|c|c|}
\hline Variable & Categories & $\begin{array}{l}\text { No of } \\
\text { subjects }\end{array}$ & $\begin{array}{l}\text { No undergoing } \\
\text { revascularisation }\end{array}$ & $\begin{array}{c}\text { No } \\
\text { censored }\end{array}$ & $\begin{array}{l}\text { Median time to } \\
\text { angioplasty (days) }\end{array}$ & $x^{2}$ & $p$ Value \\
\hline Age (years) & $\begin{array}{l}\text { Under } 45 \\
45-64 \\
65+\end{array}$ & $\begin{array}{l}12 \\
73 \\
21\end{array}$ & $\begin{array}{l}12 \\
62 \\
19\end{array}$ & $\begin{array}{r}0 \\
11 \\
2\end{array}$ & $\begin{array}{r}7 \\
28 \\
14\end{array}$ & $8 \cdot 15$ & 0.017 \\
\hline Body mass index & $\begin{array}{l}\text { under } 25 \\
25-29 \\
30+\end{array}$ & $\begin{array}{l}44 \\
46 \\
16\end{array}$ & $\begin{array}{l}38 \\
42 \\
13\end{array}$ & $\begin{array}{l}6 \\
4 \\
3\end{array}$ & $\begin{array}{l}27 \\
14 \\
41\end{array}$ & 0.09 & 0.637 \\
\hline Sex & $\begin{array}{l}\text { Male } \\
\text { Female }\end{array}$ & $\begin{array}{l}83 \\
23\end{array}$ & $\begin{array}{l}74 \\
19\end{array}$ & $\begin{array}{l}9 \\
4\end{array}$ & $\begin{array}{r}26 \\
7\end{array}$ & $0 \cdot 03$ & $0 \cdot 868$ \\
\hline Marital status & $\begin{array}{l}\text { Married } \\
\text { Single } \\
\text { Divorced/widowed/ } \\
\text { separated } \\
\text { Missing data }\end{array}$ & $\begin{array}{l}82 \\
11 \\
11 \\
2\end{array}$ & $\begin{array}{l}71 \\
10 \\
10\end{array}$ & $\begin{array}{r}11 \\
1 \\
1\end{array}$ & $\begin{array}{r}23 \\
9 \\
7\end{array}$ & 1.63 & $0 \cdot 443$ \\
\hline Employment status & $\begin{array}{l}\text { Active }^{\star} \\
\text { Inactive } \\
\text { Missing data }\end{array}$ & $\begin{array}{r}56 \\
48 \\
2\end{array}$ & $\begin{array}{l}49 \\
42\end{array}$ & $\begin{array}{l}7 \\
6\end{array}$ & $\begin{array}{l}14 \\
28\end{array}$ & 0.17 & 0.679 \\
\hline Smoking status & $\begin{array}{l}\text { Current } \\
\text { Non+ex } \\
\text { Missing data }\end{array}$ & $\begin{array}{r}40 \\
65 \\
1\end{array}$ & $\begin{array}{l}35 \\
58\end{array}$ & $\frac{5}{7}$ & $\begin{array}{l}23 \\
14\end{array}$ & $0 \cdot 08$ & 0.775 \\
\hline Referral hospital & $\begin{array}{l}\text { Belfast Hospital } \\
\text { Other }\end{array}$ & $\begin{array}{l}64 \\
42\end{array}$ & $\begin{array}{l}55 \\
38\end{array}$ & $\begin{array}{l}9 \\
4\end{array}$ & $\begin{array}{l}14 \\
20\end{array}$ & $1 \cdot 21$ & 0.271 \\
\hline Distance quintile & $\begin{array}{l}1 \dagger \\
2 \\
3 \\
4 \\
5 \\
\text { Missing data }\end{array}$ & $\begin{array}{r}24 \\
15 \\
19 \\
24 \\
20 \\
4\end{array}$ & $\begin{array}{l}21 \\
14 \\
17 \\
19 \\
19\end{array}$ & $\begin{array}{l}3 \\
1 \\
2 \\
5 \\
1\end{array}$ & $\begin{array}{r}9 \\
14 \\
28 \\
14 \\
52\end{array}$ & $1 \cdot 86$ & 0.761 \\
\hline Deprivation quintile & $\begin{array}{l}1 \ddagger \\
2 \\
3 \\
4 \\
5 \\
\text { Missing data }\end{array}$ & $\begin{array}{r}20 \\
24 \\
17 \\
21 \\
20 \\
4\end{array}$ & $\begin{array}{l}19 \\
24 \\
15 \\
15 \\
17\end{array}$ & $\begin{array}{l}1 \\
0 \\
2 \\
6 \\
3\end{array}$ & $\begin{array}{r}7 \\
7 \\
47 \\
69 \\
7\end{array}$ & $13 \cdot 96$ & 0.007 \\
\hline $\begin{array}{l}\text { History of myocardial } \\
\text { infarction }\end{array}$ & $\begin{array}{l}\text { Yes } \\
\text { No }\end{array}$ & $\begin{array}{l}60 \\
46\end{array}$ & $\begin{array}{l}52 \\
41\end{array}$ & $\begin{array}{l}8 \\
5\end{array}$ & $\begin{array}{r}8 \\
49\end{array}$ & $1 \cdot 41$ & $0 \cdot 236$ \\
\hline $\begin{array}{l}\text { Family history of } \\
\text { ischaemic heart disease }\end{array}$ & $\begin{array}{l}\text { Positive } \\
\text { Negative }\end{array}$ & $\begin{array}{l}58 \\
48\end{array}$ & $\begin{array}{l}48 \\
45\end{array}$ & $\begin{array}{r}10 \\
3\end{array}$ & $\begin{array}{l}27 \\
10\end{array}$ & $1 \cdot 1$ & $0 \cdot 295$ \\
\hline Comorbidity $\S$ & $\begin{array}{l}\text { Present } \\
\text { Absent }\end{array}$ & $\begin{array}{l}51 \\
55\end{array}$ & $\begin{array}{l}45 \\
48\end{array}$ & $\begin{array}{l}6 \\
7\end{array}$ & $\begin{array}{l}26 \\
14\end{array}$ & $0 \cdot 8$ & $0 \cdot 37$ \\
\hline Angina severity & $\begin{array}{l}\text { I } \\
\text { II } \\
\text { III } \\
\text { IV or Unstable } \\
\text { Missing data }\end{array}$ & $\begin{array}{r}42 \\
31 \\
19 \\
12 \\
2\end{array}$ & $\begin{array}{l}34 \\
28 \\
19 \\
11\end{array}$ & $\begin{array}{l}8 \\
3 \\
0 \\
1\end{array}$ & $\begin{array}{r}8 \\
33 \\
9 \\
20\end{array}$ & $4 \cdot 17$ & $0 \cdot 243$ \\
\hline $\begin{array}{l}\text { Recent history of } \\
\text { myocardial infarction }\end{array}$ & $\begin{array}{l}\text { Yes } \\
\text { No }\end{array}$ & $\begin{array}{l}60 \\
46\end{array}$ & $\begin{array}{l}52 \\
41\end{array}$ & $\begin{array}{l}8 \\
5\end{array}$ & $\begin{array}{r}8 \\
49\end{array}$ & $1 \cdot 41$ & $0 \cdot 236$ \\
\hline Number of vessels stenosed & $\begin{array}{l}0-1 \\
2 \\
3 \text { or more }\end{array}$ & $\begin{array}{l}59 \\
33 \\
14\end{array}$ & $\begin{array}{r}52 \\
32 \\
9\end{array}$ & $\begin{array}{l}7 \\
1 \\
5\end{array}$ & $\begin{array}{r}9 \\
20 \\
69\end{array}$ & $5 \cdot 91$ & 0.052 \\
\hline Treadmill test & $\begin{array}{l}\text { Definitely +ve } \\
\text { Other }\end{array}$ & $\begin{array}{l}34 \\
72\end{array}$ & $\begin{array}{l}62 \\
31\end{array}$ & $\begin{array}{r}10 \\
3\end{array}$ & $\begin{array}{r}9 \\
57\end{array}$ & 1.67 & $0 \cdot 197$ \\
\hline
\end{tabular}

^Employed $v$ unemployed patients, housewives, and retired patients combined.

tQuintile of distance from the angioplasty centre.

\pm Quintile of deprivation ranked by Townsend deprivation score.

Q Quintile of deprivation ranked by Townsend deprivation score.
oHistory of treatment for hyperlipidaemia, hypertension, or diabetes.

ICanadian Cardiovascular Society grade.

patients, retired patients, and housewives) were 0.6 times less likely than economically active (employed) patients to receive angioplasty during follow up.

Although there was a significant association between waiting time and the relative depri-

Table 2 Relative hazards derived from Cox's proportional hazards analysis: clinical and non-clinical predictors of waiting time

\begin{tabular}{|c|c|c|c|}
\hline Variable & $\begin{array}{l}\text { Relative hazard ( } 95 \% \\
\text { confidence intervals) }\end{array}$ & $x^{2}(d f)$ & $\begin{array}{c}p \\
\text { Values }\end{array}$ \\
\hline $\begin{array}{l}\text { Severity of angina: } \\
\text { II } v \text { I } \\
\text { III } v \text { I } \\
I^{\star} v \text { I }\end{array}$ & $\begin{array}{l}1 \cdot 74(0 \cdot 81 \text { to } 3 \cdot 74) \\
3 \cdot 14(1.44 \text { to } 6 \cdot 81) \\
2 \cdot 69(1.18 \text { to } 6 \cdot 15)\end{array}$ & $9 \cdot 47(3)$ & 0.024 \\
\hline History of infarction & $2 \cdot 47(1.27$ to 4.81$)$ & $6 \cdot 60(1)$ & 0.010 \\
\hline $\begin{array}{l}\text { “Deprivation” } \dagger \\
\mathrm{Q} 2 v \mathrm{Q} 1 \\
\mathrm{Q} 3 v \mathrm{Q} 1 \\
\mathrm{Q} 4 v \mathrm{Q} 1 \\
\mathrm{Q} 5 v \mathrm{Q} 1\end{array}$ & $\begin{array}{l}1.49(0.80 \text { to } 2 \cdot 77) \\
1.00(0.49 \text { to } 2 \cdot 06) \\
0.35(0.17 \text { to } 0.74) \\
0.75(0.35 \text { to } 1.59)\end{array}$ & $16 \cdot 51(4)$ & 0.002 \\
\hline $\begin{array}{l}\text { Economically } \\
\text { inactive } v \text { active } \ddagger\end{array}$ & $0.65(0.41$ to 1.05$)$ & $3 \cdot 20(1)$ & $0 \cdot 07$ \\
\hline
\end{tabular}

vation of the patient's area of residence, it showed no linear trend. The figure $(a-d)$ shows the univariate relation between the interval from angiography to angioplasty and these variables.

Because there was no clear linear trend, the model containing the variables shown in table 2 , was further investigated by attempting to fit, one at a time, terms for the possible two way interactions. None of these were significant.

\section{Discussion}

Although the Clinical Standards Advisory Group noted wide variation between hospitals in waiting times for revascularisation, it recognised that any meaningful assessment of the prioritisation process would require more detailed information on workload and case mix. ${ }^{1}$ Unlike the Clinical Standards Advisory Group study, however, the effect of commissioning on waiting times was not part of our focus. Although there are four health boards purchasing these services, live contracts did not come into operation until April 1992 and for 

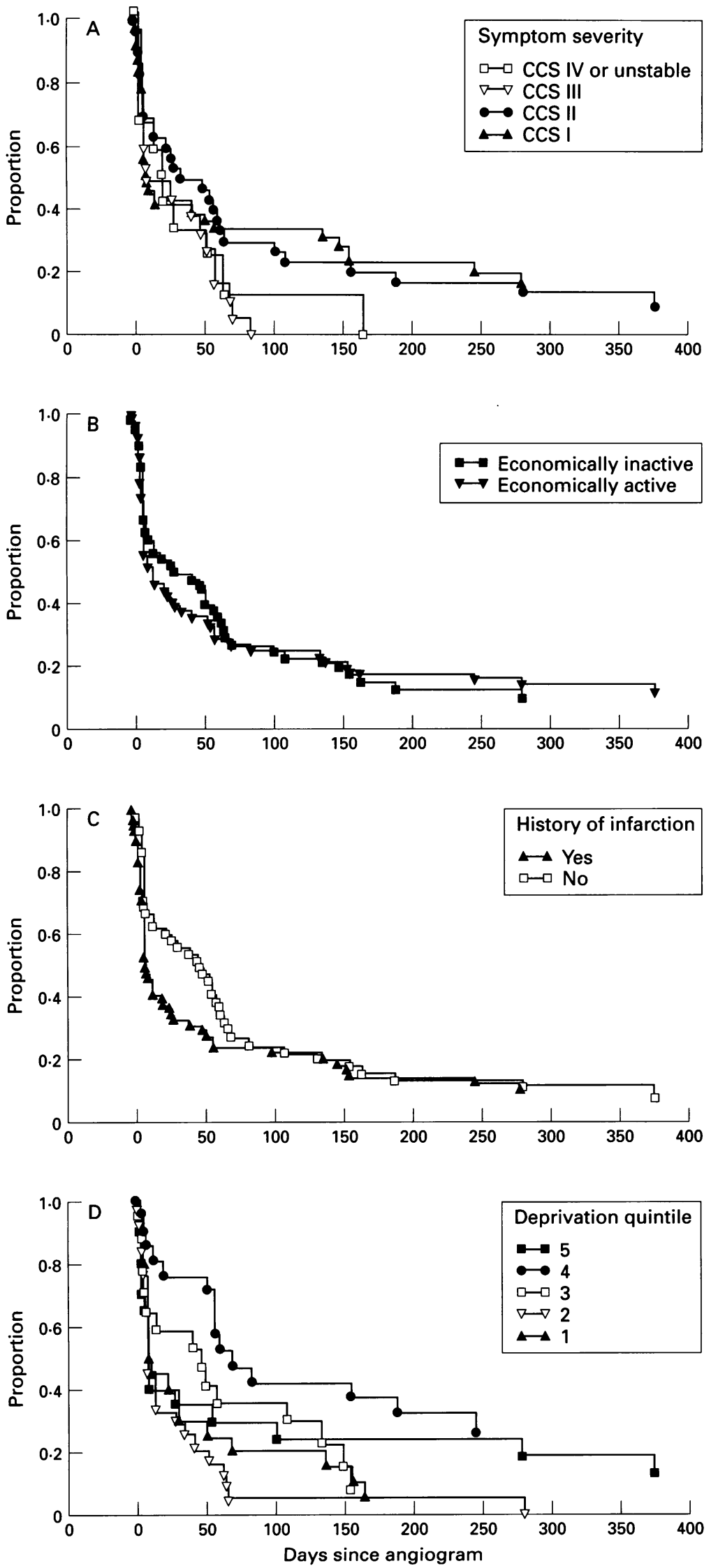

Proportion of patients still awaiting intervention: relation to: (A) symptom severity, (B) economic activity status, (C) history of infarction, (D) deprivation quintile (CCS = Canadian Cardiovascular Society grade)

the first year thereafter, regional services (such as angioplasty), remained "in steady state". The chief medical officer for Northern Ireland, however, had already drawn attention to anecdotal evidence of perceived inequity in the queuing process brought about in many instances, he surmised, by poor channels of communication between general practitioners, district hospital physicians, and cardiologists.

There are few studies to compare ours with directly because the focus of much previous work has been on surgical revascularisation. In a comparison of three hospitals in Ontario, Canada, waiting times for revascularisation were twice as long for patients who were catheterised by off site cardiologists than those referred by on site practitioners. ${ }^{12}$ In another study patients admitted with acute myocardial infarction to hospitals with a cardiac surgery service on site were found to be more likely to receive revascularisation within six months than patients initially presenting to a hospital without this service. ${ }^{20}$ Therefore, at least for some, our results will be reassuring, for whereas in other parts of the United Kingdom proximity to a surgical centre may affect a patient's chances of ever receiving bypass surgery, ${ }^{13} 21$ the distance decay effect does not seem to apply to waiting times for angioplasty in Northern Ireland. Nor do our findings suggest evidence of obvious institutional biases. This possibility had been a concern before the chief medical officer's report.

The most important clinical predictors of waiting time were severity of symptoms (the presence of severe stable angina or unstable angina) and a history of recent myocardial infarction. Arguably, the adequacy of any prioritisation process should be gauged by the extent to which the first patients treated are those most likely to benefit from intervention. Unfortunately the type of patient most likely to benefit from percutaneous transluminal coronary angioplasty (let alone to benefit from early intervention) is not yet defined. For instance, in the randomised intervention treatment of angina (RITA) trial only $4 \cdot 8 \%$ of patients potentially eligible for revascularisation were actually randomised and a specific exclusion criterion was the presence of "symptoms requiring immediate intervention" 22 ; in that trial at least, such symptoms were not explicitly defined. It is difficult to be sure whether or not they were symptoms associated with a particular angiographic coronary anatomy. Patients with left main stem disease should have already been excluded. Furthermore, it seems that for the very high risk group of patients with evolving myocardial infarction, thrombolysis and conservative management yield myocardial salvage rates as high as immediate angioplasty. ${ }^{23}$ The findings of the recently reported thrombolysis in myocardial infarction (TIMI) IIIB trial may also be relevant. ${ }^{24}$ Two investigative strategies (after thrombolysis) in patients with unstable angina or non- $Q$ wave infarction were compared. The first was an early invasive strategy of routine catheterisation (within one or two days) followed, when possible, by revascularisation. The second was an early conservative strategy that reserved angiography for patients having spontaneous ischaemia or evoked ischaemia on stress testing. Although patients managed conservatively needed more antianginal medication and stayed longer in 
hospital, there was no significant difference in the rate of myocardial infarction or death between the two groups $(6.5 \% v 8.2 \%)$ when assessed six weeks after randomisation.

Although $97 \%$ of patients who had percutaneous transluminal coronary angioplasty in the RITA trial had the procedure performed within three months of randomisation, nearly one fifth underwent a second within six months and the risk of a repeat procedure was unrelated to the number of treatable vessels at randomisation. ${ }^{21}$

Given that the primary use of angiography was, until recently, for single vessel disease, we are not surprised at the lack of association between waiting time and the number of diseased coronary vessels. Nevertheless, most patients participating had either severe angina or a history of myocardial infarction and our own findings therefore probably reflect a similar importance being ascribed to the clinical presentation. Indeed the extent and severity of stenoses alone helps very little in predicting the outlook for an individual patient and most myocardial infarctions are probably associated with thrombosis and rupture of previously non-critical stenoses..$^{25}$ It is salutary to remember, however, that the incidence of unstable angina is considerably higher after percutaneous transluminal coronary angioplasty than after coronary artery bypass grafting. ${ }^{21}$

The tendency for economically active patients to wait for shorter periods than the economically inactive patients, accords with findings from a recent survey of 120 Canadian specialists, in which patients' work status affected the priority for revascularisation accorded them as much as clinical factors. ${ }^{13}$ In our study employment status was assessed at the time of angiography from the medical notes and from the nursing care plan and admission slip (both of which had computer generated fields for this variable, to facilitate claims for travel expenses by relatives of unemployed patients). A prospective study would be better suited for determining the true nature of the association. Our results are consistent, however, with those from a recent survey of management of angina by general practitioners in Northern Ireland in which about one in five said that they would accord employed patients and those with dependents a higher priority for revascularisation than unemployed patients or those without dependents. $^{27}$

In a recently reported longitudinal study, patients on a low income were almost twice as likely to die within five years of angiography. ${ }^{28}$ Also, the number of people dependent on the household income was inversely related to survival. $^{29}$ The tendency to refer employed patients sooner for angiography thus seems contrary to the known risks.

Conceivably, clinicians consider that the benefits of early revascularisation could enhance the quality of more than one life if a bread winner is returned to productivity. Doctors are not immune from making value judgements such as these. ${ }^{25}$
Although smoking, as declared by the patient and recorded in the hospital notes, did not seem to have a bearing on waiting time, the patients studied - those who had already undergone angiography - are, by definition, a preselected group. It is conceivable that the distribution of total waiting times, either from time of first clinical diagnosis or from time of first hospital referral might have been different for smokers and non-smokers. Among the larger group of 500 patients from which the present sample was drawn, smoking was not significantly associated with total duration of history of angina. ${ }^{14}$ Anecdotally, however, it is known that some cardiologists will delay performing an exercise treadmill test until the patient stops smoking, predicting that the patient's "suitability" for revascularisation would be otherwise affected. Indeed, in our survey of management of angina by general practitioners $37 \%$ of doctors said they were likely to refer non-smokers earlier than smokers. ${ }^{27}$

Although there was an association between waiting time and the relative deprivation of the patient's usual area of residence, no clear trend was apparent. In so far as the ability of patients to describe their symptoms adequately (or bring them to the attention of their doctors) may be correlated with their material affluence, this might, in part, be an explanation for our findings. In one recent study disadvantaged patients were less likely to attribute symptoms to a cardiac origin. ${ }^{29}$ Other evidence suggests that the way in which patients present their symptoms may affect clinical decision making, ${ }^{30} 31$ even when cardiologists are presented with identical clinical data. Although we must be careful to avoid overinterpretation of the data, particularly because of the lack of a consistent trend and the possibility of residual confounding, our findings merit further study. A larger more powerful study could usefully investigate the potential for interaction between the effects of the biological and demographic factors on waiting time - for instance, is the effect of angina grade attenuated or enhanced for patients from affluent areas or for the employed?

We consider this work to be only a first step in describing the clinical and non-clinical factors that influence waiting time but, as such, it has attempted to go beyond the work of the Clinical Standards Advisory Group. ${ }^{1}$ We must set the work in context and apply some caveats to our conclusions. Our sample, although randomly selected, is of modest size and we have relied on data abstracted from the medical records. We believe it unlikely, however, that misclassification could account for the main effects found and the basic methodology, which has much in common with audit, has been used successfully in assessing the "appropriateness" of revascularisation. ${ }^{32}$ The use of aggregate socioeconomic data is a potential shortcoming and the sort of analysis used in this study is obviously susceptible to the "ecological fallacy" if it turned out, for example, that relatively well off patients from the poor areas were the ones receiving angioplasty sooner, or vice versa. 
Nevertheless, the method has been considered to be robust ${ }^{33}$ and, in our particular analysis it probably biases the estimated relation between socioeconomic status and waiting time towards the null value. ${ }^{34}$

A further potential shortcoming in our study was the reliance on a retrospective collection of data. Our methods are, however, typical of most other studies on the topic. ${ }^{812} 1935$ Whereas some doctors may be unaware of sociological influences on their prioritisation decisions, the act of observation in a prospective study might itself bias the decision making process. In fact some have argued for more explicit consideration of societal benefits in medical decision making, implying the need for constructing a "SQALY" - a social quality adjusted life year (QALY) - in evaluating health service interventions. ${ }^{36}$ This approach may have some logic, but it begs the underlying question of what constitutes individual need for health care.

Harris has argued that the value of life can only sensibly be taken to be that value that those alive place on their lives. ${ }^{37}$ It may be that society should place greater store on some people's capacity to benefit from health service interventions to maximise productivity and therefore the overall social welfare available. The scrutiny and justification of such decisions, however, cannot and must not be the preserve of doctors alone. ${ }^{38}$

Although the study might provide useful feedback to clinicians who will respond to the chief medical officer's call for consensus on prioritisation criteria, it is to be expected that local guidelines may not "travel well." Angioplasty rates in Northern Ireland at the time of the chief medical officer's report were roughly twice those in most of the rest of the United Kingdom. ${ }^{3}$ Nevertheless, United Kingdom rates are still among the lowest in Europe. Despite the very high demand on the two catheterisation laboratories the median time between angiography and percutaneous transluminal carotid angioplasty was still only 20 days. Centres in other regions face different workloads and, unlike the situation in Northern Ireland in 1991, commissioning activities may have brought about much more patient traffic across district and regional boundaries, a potential distorting influence on local decision making for prioritisation.

1 Report of a CSAG working group chaired by Sir Terence English. Coronary artery bypass grafting and coronary angioplasty. Access to and availability of specialist services. London: HMSO, 1993.

2 The Scottish Office. Home and Health Department. 1992 Health in Scotland. London: HMSO, 1992.

3 Department of Health and Social Services. Review of cardiac surgery in Northern Ireland. A report by the Chief Medical Officer. Belfast: Department of Health and Social Officer. Belfast:
Services, 1992 .

4 Brook R, Kosecoff J, Park R, Chassin M, Winslow C, Hampton J. Diagnosis and treatment of coronary disease: Hampton J. Diagnosis and treatment of coronary disease: Comparison of doctors' a

5 Gray D, Hampton J, Bernstein S, Kosecoff J, Brook R. Audit of coronary angiography and bypass surgery. Lancet 1990;335:1317-20.

6 Bernstein S, Kosecoff J, Gray D, Hampton J, Brook R. The appropriateness of the use of cardiovascular procedures. British versus US experience. Int $\mathcal{F}$ Technol Assess Health Care 1993;9:3-10.

7 Naylor CD, Basinski A, Baigrie R, Goldman B, Lomas J. Placing patients in the queue for coronary revascular- isation: evidence for practice variations from an expert panel process. Am F Public Health 1990;80:1246-52.

8 Naylor CD, Baigrie R, Goldman B, Basinski A. Assessment of priority for coronary revascularisation procedures. Lancet 1990;335:1070-3.

9 Naylor D. A different view of queues in Ontario. Health Aff (Millwood) 1990;10:110-128.

10 Naylor CD, Levinton C, Baigrie RS. Adapting to waiting lists for coronary revascularisation. Do Canadian specialists agree on which patients come first? Chest 1992; 101:715-22.

11 Naylor CD, Levinton C, Baigrie R, Goldman B. Placing patients in the queue for coronary surgery: do age and work status alter Canadian specialist's decisions? $\mathcal{F}$ Gen Intern Med 1992;7:492-8.

12 Naylor D, Levinton C, Wheeler S, Hunter L. Queueing for coronary surgery during severe supply-demand mismatch in a Canadian referral centre: a case study of implicit rationing. Soc Sci Med 1993;37:61-7.

13 Majeed FA, Chaturvedi N, Reading R, Ben-Shlomo Y. Monitoring and promoting equity in primary and secondary care. $B M \mathcal{F}$ 1994;308:1426-9.

14 Gaffney B, Kee F. Are the economically active more deserving? Br Heart $\mathcal{f}$ 1995;73:385-9.

15 Cox J, Naylor D. The Canadian Cardiovascular Society grading scale for angina pectoris: is it time for refinements? Ann Intern Med 1992:117:677-83.

16 Cox J, Naylor D, Johnstone DE. Limitations of Canadian Cardiovascular Society classification of angina pectoris. Am $\mathcal{F}$ Cardiol 1994;74:276-7.

17 Spatial and social variations in the distribution of health indicators in Northern Ireland. The Queen's University, Belfast: Policy Research Institute, 1990.

18 Armitage P, Berry G. Statistical methods in medical research. 2nd ed. Oxford: Blackwell, 1987.

19 Cox DR. Regression models and life tables. Fournal of the Royal Statistical Society 1972;34:187-220.

20 Blustein J. High technology cardiac procedures. The impact of service availability on service use in New York State. of service availability on

21 Ben-Shlomo Y, Chaturvedi N. Assessing equity in access to health care provision in the UK. Does where you live affect your chance of getting CABG. $\mathcal{F}$ Epidemiol Community Health 1995;49:200-4.

22 RITA Trial Participants. Coronary angioplasty versus coronary bypass surgery: the Randomised Intervention Treatment of Angina Trial. Lancet 1993;341:573-80.

23 Gibbons RJ, Holmes DR, Reeder G, Bailey K, Hopfenspirger M, Gersh BJ, et al. Immediate angioplasty compared with the administration of a thrombolytic agent followed by conservative treatment for myocardial infarction. N Engl F Med 1993;328:685-91.

24 The TIMI IIIB Investigators. Effects of tissue plasminogen activator and a comparison of early invasive and conservative strategies in unstable angina and non-Q-wave myocardial infarction. Circulation 1994;89:1545-56.

25 Patterson D, Treasure T. The culprit coronary lesion. Lancet 1991;338:1379-80.

26 Casscells W, Ferguson J, Willerson JT, Fish R, Schroth G, Smalling $R$, et al. Thrombus and unstable angina. Report of a meeting of physicians and scientists, Texas Heart Institute and the University of Texas Medical School at Houston. Lancet 1993;342:1151-5.

27 Kee F, Gaffney B, Canavan C, Little J, McConnell W, Telford AM, et al. Having your coronary arteries studied? Is choosing your doctor important? Quality in Health Care Is choosing your

28 Williams RB, Barefoot JC, Califf RM, Haney TL, Saunders WB, Pryor DB, et al. Prognostic importance of social and economic resources among medically treated patients with angiographically documented coronary artery disease. $\mathcal{F A M A} 1992 ; 267: 520-4$.

29 Racznski J, Taylor H, Cutter G, Hardin M, Rappaport N, Oberman A. Diagnoses, symptoms and attribution of symptoms among black and white inpatients admitted for coronary heart disease. Am $\mathcal{F}$ Public Health 1994;84: 951-6.

30 Bobbio M, Detrano, Shandling A, Ellestad M, Clark J, Brezden $\mathrm{O}$, et al. Clinical assessment of the probability of coronary artery disease: judgmental bias from personal knowledge. Med Decis Making 1992;12:197-203.

31 Birdwell B, Herbers J, Kroenke K. Evaluating chest pain. The patient's presentation style alters the physicians diagnostic approach. Arch Intern Med 1993;153:1991-95.

32 Bernstein SJ, Kosecoff J, Gray D, Hampton J, Brook RH. The appropriateness of the use of cardiovascular procedures. British versus US perspectives. Int $\mathcal{f}$ Technol Assess Health Care 1993;9:3-10.

33 Kreiger N. Overcoming the absence of socioeconomic data in medical records: validation and application of a censusbased methodology. Am f Public Health 1992;92:703-10.

34 Greenwald HP, Polissar NL, Borgatta E, McCorkle R. Detecting survival effects of socio-economic status: problems in the use of aggregate measures. $f$ Clin Epidemiol 1994;47:903-9.

35 Fitzpatrick MA. Audit of prioritisation for coronary revascularisation procedures: implications for rationing. NZ Med f 1992;105:145-7.

36 Nord E. The significance of contextual factors in valuing health states. Health Policy 1989;13:189-98.

37 Harris J. Qualifying the value of life. $\mathcal{F}$ Med Ethics 1987;13: 117-23.

38 Hope T, Sprigings D, Crisp R. "Not clinically indicated": patients or resource allocations? $B M \mathcal{F} 1993 ; 306: 379-81$. 